\title{
In-vitro Comparison of Dissolution Efficacy of Refined Orange oil over Xylene on Various Forms of Gutta Percha.
}

\author{
Atul Jain ${ }^{1}$, Bharat Choudhary ${ }^{2}$, Nakul Patidar ${ }^{3}$, Kanchan Bhadoria ${ }^{4}$, \\ Arvind M.S. ${ }^{5}$ \\ ${ }^{1}$ Professor And Head Of The Department, Department Of Conservative Dentistry And Endodontics, R.K.D.F \\ Dental College And Research Centre, Bhopal \\ ${ }^{2,3,4}$ Post Graduate Student, Department Of Conservative Dentistry And Endodontics, R.K.D.F Dental College \\ And Research Centre, Bhopal) \\ ${ }^{5}$ Reader, Department Of Conservative Dentistry And Endodontics, R.K.D.F Dental College And Research \\ Centre, Bhopal)
}

\begin{abstract}
For successful endodontic re-treatment, complete removal of fillingfrom the root canals is essential.Towards this end, solvents are indispensible.Thisstudy was carried out to compare and evaluate the dissolving capability of refined orange oil over xylene on various forms of gutta percha.30, ISO No. 40, 2\% taper cones of Gutta Percha, Chlorhexidine Active points and Calcium hydroxide plus pointseach, were selected and placed in Group A, B and C respectively. Each group was further subdivided into two subgroups, which were treated with Xylene and Orange Oil solvent respectively, for 5 minutes, at room temperature. Each sample was weighed before and after immersion on a digital analytical scale.Data obtained was subjected to paired 't' test,one way ANOVA test and scheffe's test. Results shows that the weight loss of all types of gutta percha was more in Xylene thanOrange oil but the difference was not statistically significant.Orange oil can be used as an effective guttta percha solvent.
\end{abstract}

Keywords: Calcium Hydroxide, Chlorhexidine, Gutta-Percha, Solubility, Solvents, Weight Loss

\section{Introduction}

In an obturated root canal, failure may arise because of coronal or apical leakage. This re-infection may lead to endodontic failure. To re-establishhealthy periapical tissues, nonsurgical endodontic retreatment is required. Towards this end, adequate cleaning and shaping along with proper access, is mandatory to completely eliminate the pathogens and re-obturate the canal system.[1] Endodontic retreatment can successfully eliminate the pathology[2] and re-establish healthy periapical tissue.

Guttapercha (GP) is the most popular core material used forobturation that fulfilsthe majority of criteria but itlacks an effective seal andadhesion.This can result incontamination,bacterial penetrationand iatrogenic failuresthatmay contribute to the failure of the treatment.[3]Therefore it needs to be combined with a sealer to obtain a tight seal. For cases requiring intra-canal medication, two type of medicated GP are available commercially - Calcium hydroxide points or plus points (CaP), containing $58 \%$ calcium hydroxide and $42 \%$ guttapercha and Chlorhexidine active points(ChxP) that contain5\% Chlorhexidine diacetate. $[4,5]$

In re-treatment situations, GP removal can be achieved by various conventional as well as advanced techniques, including rotary files, ultrasonic instruments, and hand files in combination with heat or chemicals.[6,7] Use of chemical solvents as an adjunct in removal of root canal filling material is quite pervasive. With the use of medicated GP, as an intracanal medicament, for an extended period of time, their complete removal becomes difficult. [8] In such situations, use of a GP solvent is helpful. Some of the commonly used solvents are- Chloroform, Halothane, Tetrachloroethylene and Xylene. Out of these Xylene is themost widely used, having good efficiency but possessing side effects, like depression of CNS, irritability, insomnia, agitation, extreme fatigue, tremors, impaired concentration, heart and liver pathosis, fatal blood dyscrasias, skin erythema, drying and scaling of skin. $[9,10]$ Lately Orange oil, an extract of the peel of sweet orange fruit has been advocated as an effective GP solvent,[11]possessing least toxic potential. [12].In order to test the efficacy of Orange oil over Xylene, as an effective GP solvent,this study was carried out.

\section{Materials And Method}

This in vitro study was carried out in the department of Conservative Dentistry and Endodontics, R.K.D.F Dental College and Research Centre,Bhopal (M.P.)A total of 90, ISO No. 40, $2 \%$ taper cones were taken up in this study. They consisted of 30 cones of Gutta Percha (SureEndo, Korea), 30 Chlorhexidine Active points(Roeko, COLTENE, Germany) and 30 Calcium hydroxide plus points (Roeko,COLTENE, Germany). They were distributed in three groups- A, B and C, wherein Group A consisted of Gutta Percha, B of 
Chlorhexidine active points and Group C of Calcium hydroxide plus points. Each group was further subdivided into two subgroups- 1 and 2. Samples in sub-group 1 were treated with Xylene solvent (Trulon, Ghaziabad, India) and those in sub-group 2 with Orange Oil solvent (Neelkanth,India) respectively. (Table 1)

Each sample was weighed initially, before immersing in the solvent, on a digital analytical scale (KEERO, JAPAN). Subsequently each sample was separately immersed, for a period of 5 minutes, in $5 \mathrm{ml}$ of the respective solvent (as per the sub-group distribution) at room temperature, in a glass test tube. Each test tube was covered with aluminium foil to prevent evaporation of the solvent.Test tubes were placed on vibrator at a frequency of 3000 cycles/minute,to prevent clumping of the partially dissolved GP. Each sample wasremoved from the glass tubes after the specified immersion period, washed in $100 \mathrm{ml}$ of distilled water, dried for $24 \mathrm{~h}$ at $37^{\circ} \mathrm{C}$ in a humidifier and was again weighted on the digital analytical scale.

The amount of mass lost from each sample was calculated by the formula:[1]

$\mathrm{M}=\mathrm{M} 1-\mathrm{M} 2$

[Where:M=Mass lost

M1=Pre - immersion weight

M2=Post - immersion weight $]$

Mass lost was calculated and data were subjected for statistical analysis. The average mean weight loss was analysed using software SPSS version 16.0. Paired t test was carried out to evaluate the pre and post immersion weight loss. One way ANOVA test was carried out for comparing the mean dissolution between groups. Multiple comparison of dissolution capability between individual subgroups was carried out by Scheffe's test.

\section{Results}

The average weight loss observed in GP, ChxP and CaP with Xylene was found to be $0.01627 \mathrm{gm}$, $0.01546 \mathrm{gm}$ and $0.01827 \mathrm{gm}$, whereas with Orange oil, it was found to be $0.01333 \mathrm{gm}, 0.01733 \mathrm{gm}$ and 0.01547 gm respectively.The observed weight loss of all the three types in Xylene was greater than that in Orange oil but it was statistically non-significant. (Table 1)With Xylene, there was no statistically significant difference in weight loss between GP and $\mathrm{ChxP}$ but it was significant between $\mathrm{CaP}$ and the other types. (Table 2) In Orange oil solvent similar weight loss was observed between GP and ChxP, which was statistically not significant, whereas it was more and statistically significant between $\mathrm{CaP}$ and the other two.(Table 3) The weight loss observed across the three types of GP points was found to be greater with xylene then orange oil, through this weight loss was statistically nonsignificant.

\section{Discussion}

The medicated gutta perchawhen placed within the root canal tend to release the respective medicament. Calcium and Chlorhexidine have been found to cleng on the dentinal wall even after repeated instrumentation and irrigation. In these situations use of a dissolving solvent is helpful. Similarly in endodontic re-treatment conditions, use of a solvent is helpful for complete removal of GP.[13]Easy GP removal achieved with the solvents varies depending upon the dissolution potential and removal capacity of the latter. Trying to balance the effectiveness and toxicity of the solvent, essential oils are mostly accepted because of easy availability and biocompatibility. [14]Among these, Orange oil has been found to be an effective GP solvent [15] with least toxic potential and possessing good biocompatibility. [16]Xylene dissolves the GP by disruption of covalent bonds among the carbon atoms. It produces overall better results as a solvent, by removal of residue. [17]It is not considered a potential carcinogen but has serious drawbacks in the form of producing irritation in the periapical tissues. $[18,19]$ This toxic reaction arises due to an intermediate metabolic product like methyl benzaldehyde. [20] Orange oil has been suggested as a safer and effective alternative to Xylene. [21] It brings about dissolution of GP by penetrating and separating the polymer chains. [22] It is more biocompatible and displays less cytotoxicity than Xylene. [23, 24]In our study Xylene was found to possess better dissolution for all types of GP than Orange oil. Magalhães et alalso found Xylene to have highest capability for dissolving GP.[25] Orange oil was also found to possess adequate dissolution capacity for resilon and GP cones.[26]Similar to our findings, Khedmat et al also found Orange oil to be an effective GP solvent. They also found Orange oil to be highly biocompatible with least cytotoxicity among the commonly used solvents and did not decrease the root microhardness.[27] Limonene is the active ingredient in Orange oil and isused as a less toxic substitute for Xylene in histopathology and microscopy. 3-cyclohexen-1-ol, 4-methyl-1-(1-methylethyl) which is the most abundant constituent and a derivative of limonene,is responsible for antimicrobial action.[28] Limonene reagents are advocated as potential substitute as dissolvent over Xylene with least biological hazards.[29] Considering the similarities and effectiveness ofXylene and Orange oil, Matros et al suggested use of latter over the formerfor dissolution of GP.[30] 
This study had certain limitations that the dissolution procedure was carried out in-vitro, under near ideal conditions, whereas as in the oral cavity, conditions differ. Moreover within the root canal, the number of times solvent is placed, also varies, along with the use of endodontic instruments. Thus to simulate the oral conditions, this study needs to be carried out on patients, clinically, wherein the reaction of solvents on the periapical tissues can also be assessed. Based on the results of our in-vitro study, Orange oil can be suggested as an effective GP solvent.

\section{Conclusion}

Within the limitations of this in-vitro investigation, it can be concluded that Xylene and Orange oil have similar dissolving capability for Gutta percha, Chlorhexidine active points and Calcium hydroxide plus points. Orange oil can be used as a potent and safer alternative to Xylene.

\section{Figures And Tables}

\begin{tabular}{|l|c|c|}
\hline $\begin{array}{l}\text { Group (ISO No. 40, 2\% taper) } \\
(\mathrm{n}=30)\end{array}$ & $\begin{array}{c}\text { Subgroup 1(Xylene) } \\
(\mathrm{n}=15)\end{array}$ & $\begin{array}{c}\text { Subgroup 2 (Orange Oil) } \\
(\mathrm{n}=15)\end{array}$ \\
\hline A (Gutta Percha) & $\mathrm{A} 1$ & $\mathrm{~A} 2$ \\
\hline B (Chlorhexidine Active Points) & $\mathrm{B} 1$ & $\mathrm{~B} 2$ \\
\hline C (Calcium Hydroxide Plus Points) & $\mathrm{C} 1$ & $\mathrm{C} 2$ \\
\hline
\end{tabular}

Table1: Group distribution of different GP points dissolution

\begin{tabular}{|c|c|l|l|l|}
\hline $\begin{array}{l}\text { Sub } \\
\text { groups }\end{array}$ & Number & Mean weight loss & $\begin{array}{l}\text { Standard } \\
\text { deviations }\end{array}$ & $\begin{array}{l}\text { Significance }(\mathrm{p}<0 . \\
05)\end{array}$ \\
\hline A1 & 15 & 0.01627 & 0.00243 & 0.720 \\
\hline B1 & 15 & 0.01546 & 0.00229 & 0.475 \\
\hline C1 & 15 & 0.01827 & 0.00274 & 0.006 \\
\hline
\end{tabular}

Table 2:- Weight loss of different GP points after Immersion in xylene solvent

\begin{tabular}{|l|l|l|l|l|}
\hline Sub groups & Number & Mean weight loss & $\begin{array}{l}\text { Standard } \\
\text { deviations }\end{array}$ & $\begin{array}{l}\text { Significance }(\mathrm{p}<0 . \\
05)\end{array}$ \\
\hline $\mathrm{A} 2$ & 15 & 0.01333 & 0.00244 & 0.645 \\
\hline $\mathrm{B} 2$ & 15 & 0.01733 & 0.00213 & 0.806 \\
\hline $\mathrm{C} 2$ & 15 & 0.01547 & 0.00141 & 0.118 \\
\hline
\end{tabular}

Table 3: Weight loss of different GP points after Immersion in orange oil solvent

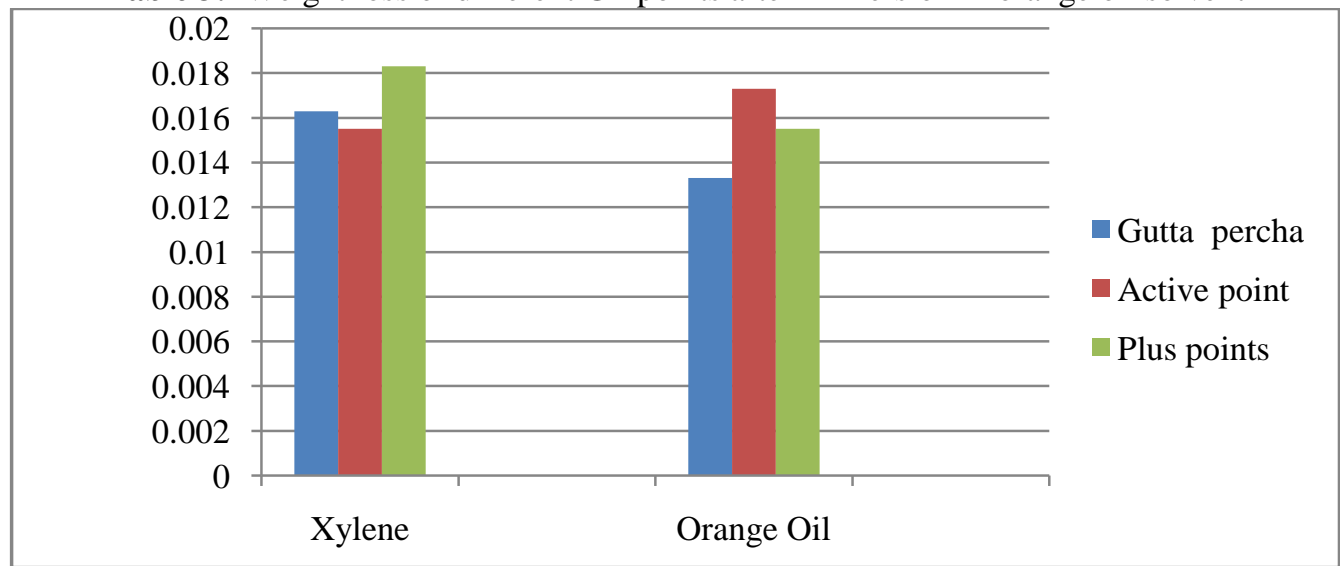

Fig 1: Comparison of solubility effect of Xylene and Orange oil on different GP points.Solubility is expressed as weight loss in grams.

\section{References}

[1]. Mushtaq M, Farooq R, Ibrahim M, Khan FY. Dissolving efficacy of different organic solvents on gutta-percha and resilon root canal obturating materials at different immersion time intervals. J Conserv Dent.2012;15:141-145.

[2]. Padmaja K, Shah A, Malpani S, Kakkar M, Thakkar R. Retreatment in Endodontics: A Review. J Adv Med Dent Scie Res.2015;3(1):205-208.

[3]. Ørstavik DA. Materials used for root canal obturation: technical, biological and clinical testing. Endodontic topics. 2005;12(1):2538.

[4]. Alagarsamy V, Ebenezar AVR, Srinivasan M. Effectiveness of calcium hydroxide plus points and chlorhexidine activ points against Enterococcus faecalis by agar diffusion test: An in-vitro study. J Rest Dent.2013;1(1):18-21.

[5]. Rossi Fedele G, Doğramacı EJ, Steier L, de Figueiredo JA. Interaction between Chlorhexidine impregnated gutta percha points and several chlorine containing endodontic irrigating solutions. Int Endod J. 2013; 46(7):675-680.

[6]. Ruddle CJ. Nonsurgical endodontic retreatment. CDA Journal. 2004; 6: 1-14. 
[7]. Horvath SD, Altenburger MJ, Naumann M, Wolkewitz M, Schirrmeister JF. Cleanliness of dentinal tubules following gutta percha removal with and without solvents: a scanning electron microscopic study. Int Endod J. 2009;42(11):1032-1038.

[8]. Lins PD, Nogueira BC, Fagundes NC, Silva FR, Lima RR. Analysis of the effectiveness of calcium hydroxide removal with variation of technique and solvent vehicles. Indian J Dent Res 2015;26:304-8.

[9]. Kandyala R, Raghavendra SP, Rajasekharan ST. Xylene: An overview of its health hazards and preventive measures. J Oral Maxillofac Pathol. 2010;14(1):1-5.

[10]. Negi A, Puri A, Gupta R, Chauhan I, Nangia R, Sachdeva A. Biosafe alternative to xylene: A comparative study. J Oral Maxillofac Pathol.2013;17:363-366.

[11]. Obidi OF, Adelowotan AO, Ayoola GA, Johnson OO, Hassan MO, Nwachukwu SC. Antimicrobial activity of orange oil on selected pathogens. The International Journal of Biotechnology. 2013; 2(6):113-122.

[12]. de Almeida G, Daniel AP, Nunes RA, Fernandes AL, Maniglia-Ferreira C, de Matos HR et al. Efficacy of gutta-percha solvents used in endodontic retreatments.RSBO. 2013;10(4):356-361.

[13]. Rehman K, Khan FR, Aman N. Comparison of orange oil and chloroform as gutta-percha solvents in endodontic retreatment. J Contemp Dent Pract.2013;14(3):478-482.

[14]. Dagli N, Dagli R, Mahmoud RS, Baroudi K. Essential oils, their therapeutic properties, and implication in dentistry: A review. J Int Soc Prevent Communit Dent. 2015;5:335-340.

[15]. Martos J, Gastal MT, Sommer L, Lund RG, Del Pino FA, Osinaga PW. Dissolving efficacy of organic solvents on root canal sealers. Clin Oral Invest. 2006;10(1):50-54.

[16]. Rubino GA, Akisue E, Nunes BG, Gavini G. Solvency capacity of gutta-percha and resilon using chloroform, eucalyptol, orange oil or xylene. J Health Sci Inst. 2012;30(1):22-5.

[17]. Cavenago BC, Ordinola Zapata R, Duarte MA, Carpio Perochena AE, Villas Bôas MH, Marciano MA et al. Efficacy of xylene and passive ultrasonic irrigation on remaining root filling material during retreatment of anatomically complex teeth. Int Endod J. 2014;47(11):1078-1083.

[18]. Sermadi W, Prabhu S, Acharya S, Javali SB. Comparing the efficacy of coconut oil and xylene as a clearing agent in the histopathology laboratory.J Oral Maxillofac Pathol. 2014;18:49-53.

[19]. Varri S, Chukka RS, Bolla N, Kavuri SR, Kumari S. Endodontic retreatment: Rotary versus hand instrumentation: An in vitro study. J Dr NTR Univ Health Sci.2012;1:116-119.

[20]. Toxicological profile for xylene, U.S Department of Health and Human Services, public health service, Agency for toxic substance and disease registry. 1993.

[21]. Rai R, Yadav R, Bhardwaj A. BIOSAFE SUBSTITUTES TO XYLENE: A REVIEW.Int J Inform Res Rev. 2016; 3(6): 2529-2532.

[22]. Jantarat J, Malhotra W, Sutimuntanakul S. Efficacy of grapefruit, tangerine, lime, and lemon oils as solvents for softening gutta percha in root canal retreatment procedures.J Investig Clin Dent. 2013;4(1):60-63.

[23]. Ramos TI, Câmara AC, Aguiar CM. Evaluation of Capacity of Essential Oils in Dissolving ProTaper Universal Gutta-Percha points. Acta stomatol Croat. 2016; 50(1):128-133.

[24]. Scelza MF, Coil JM, Maciel AC, Oliveira LR, Scelza P. Comparative SEM evaluation of three solvents used in endodontic retreatment: an ex vivo study. J Appl Oral Sci. 2008;16(1):24-29.

[25]. Magalhães BS, Johann JE, Lund RG, Martos J, Del Pino FA. Dissolving efficacy of some organic solvents on gutta-percha.Braz Oral Res. 2007;21(4):303-307.

[26]. Tanomaru-Filho M, Orlando TD, Bortoluzzi EA, Silva GF, Tanomaru JM. Solvent capacity of different substances on gutta-percha and Resilon. Braz Dent J. 2010; 21(1): 46-49.

[27]. Khedmat S, Hashemi A, Dibaji F,Effect of Chloroform, Eucalyptol and Orange Oil Solvents on the Microhardness of Human Root Dentin. J Dent (Tehran). 2015; 12(1):25-30.

[28]. Obidi OF, Adelowotan AO, Ayoola GA, Johnson OO, Hassan MO, Nwachukwu SC. Antimicrobial activity of orange oil on selected pathogens. Int J Biotechnol. 2013;2(6):113-122.

[29]. Srivastava S, Naik R, Nayak S, Nayak P, Gupta R, Malu M. Xylene and Alcohol Free H and E Staining: A Time Saving and Biosafe Alternative. Indian J Stomatol. 2015; 6(1):17-22.

[30]. Martos J, Silveira LF, Silveira CF, de Castro LA, Ferrer-Luque CM. The effect of different organic solvents on the degradation of restorative materials. Eur J Dent. 2013; 7:347-351. 